\title{
Documentário Fio: Tecendo a Profissão Docente
}

\author{
DOCUMENTARY FIO: WEAVING THE TEACHING PROFESSION
}

DOI: $10.23926 /$ RPD.2526-2149.2020.v5.n2.p843-856.id767

\section{Tiago Cerqueira Pinheiro}

Licenciando em Educação

Física (UFRJ)

Extensionista do Projeto

EEFD Baixada (UFRJ)

tiagocerqueira2013@hotmail .com

\section{Cássia Barbosa da Costa}

Pós-Graduanda em Educação

Física Escolar (IFRJ)

Extensionista do Projeto

EEFD Baixada (UFRJ)

cassia.brbs@gmail.com

\section{Renato Sarti}

Doutorando em Educação

em Ciências e Saúde (UFRJ)

Técnico em Assuntos

Educacionais na

Universidade Federal do Rio de Janeiro (UFRJ)

Professor de Educação Física na Prefeitura Municipal de

Duque de Caxias-RJ

(PMDC)

renatosarti.eefd@gmail.com
Resumo: O presente artigo tem o objetivo de apresentar o relatório da experiência desenvolvida na construção do documentário "Fio: Tecendo a profissão docente". A ação em tela teve como contexto o projeto de extensão "EEFD-Baixada: Autonomia e Construção de Conhecimento" e contou com o objetivo de contribuir para o processo de reflexão acerca da profissão docente, valorizar e socializar os desafios da profissão com os graduandos. Ancorados nos conceitos de identidade, saberes e carreira docente, o documentário teve como protagonistas cinco professores atuantes do ensino básico, de diferentes etapas da carreira profissional e de diferentes regiões do estado do Rio de Janeiro. A estrutura metodológica contou com dois momentos: apresentação do contexto de produção; e reflexão sobre as falas dos professores/atores. $\mathrm{O}$ desenvolvimento da experiência em tela possibilitou relevantes tessituras sobre a profissão docente e suas múltiplas dimensões.

Palavras-chave: Profissão Docente. Identidade Profissional. Saberes da Experiência.

\begin{abstract}
This paper aims to present the report of the experience developed in the construction of the documentary "Fio: weaving the teaching profession". The action on screen had as context the extension project "EEFD-Baixada: Autonomy and Construction of Knowledge" and had the objective of contributing to the process of reflection about the teaching profession, valuing and socializing the profession's challenges with the undergraduate students (teachers in training). The documentary found support in the concepts of Identity, Knowledge and teaching career. As protagonists of the production, the teachers interviewed are active in basic education, from different stages of their professional careers and from different regions of the state of Rio de Janeiro. The methodological structure had two moments: presentation of the production context; and reflection on the statements of teachers/actors. The development of the screen experience has enabled relevant insights about the teaching profession and its multiple dimensions.
\end{abstract}

Keywords: Teaching Profession. Professional Identity. Knowledge of Experience. 


\section{INTRODUÇÃO}

Os cursos de licenciaturas no Brasil têm guardado a responsabilidade central de formar professores para atuação na educação básica. Deste modo, tem sido crescente a preocupação com a formação docente em relação às estruturas institucionais e seus conteúdos formativos (GATTI, 2010). Atravessando esta conjuntura, a autora destaca que os desafios são múltiplos e passam também pelos planos de carreira, salários de docentes e as condições de trabalho. Neste contexto permeado de reptos, a autora destaca ainda que "as disciplinas de formação específica, predominam as abordagens de caráter mais descritivo e que se preocupam menos em relacionar adequadamente as teorias com as práticas" (GATTI, 2010, p.1.371). Assim, tem sido emergente a necessidade de refletir sobre a formação inicial docente, com destaque para a formação universitária e imperativo de aproximação com a escola e com a dinâmica profissional do professor da educação básica (NÓVOA, 2009). Também atento ao imperativo de maior interlocução entre os cursos de licenciatura e as escolas, Zeichner (2010) propõe a ideia de "terceiro espaço", ou seja, por meio de "cruzamento de fronteiras", espera-se um cenário mais dialógico entre os diversos sujeitos que atuam no processo formativo, com destaque para os professores da educação básica e seus saberes.

Nesse sentido, diante das reflexões e desafios apresentados por estes autores, qual tem sido o espaço das escolas e de seus professores na formação inicial do professor? Como os saberes dos professores da educação básica vêm atravessando a dinâmica curricular dos cursos? Quais as possibilidades de comunicação entre professores das escolas e os professores em formação nas universidades? Desse modo, dialogando com o cenário da formação de professores no Brasil e as suas problemáticas, o referido trabalho no geral tem como objetivo descrever todo o contexto de produção do documentário "Fio: Tecendo a profissão docente", dialogando com as suas bases teóricas que fundamentaram a sua idealização, a escolha dos participantes, a montagem do roteiro, as questões que são abordadas pelos mesmos, a temática da identidade docente e os desafios que tangem a profissão.

O referido documentário nasceu no horizonte de contribuir para o processo de reflexão acerca da profissão docente, valorizar e socializar os desafios da profissão com os licenciandos (professores em formação). Sua criação surgiu como uma ação do projeto de extensão "EEFD BAIXADA: Autonomia e Construção de Conhecimento", que em um de seus eixos de trabalho tem buscado olhar e, principalmente, fomentar espaços de debates que atravessem a profissão docente. No contexto deste eixo, são criadas ações que fomentam o cenário de discussão voltado à formação de professores, buscando uma construção do reconhecimento do "ser professor", 
bem como discussão sobre a prática docente e os conteúdos da Educação Física escolar. O encontro de formação e profissão docente é uma dessas ações e visa a criar cenário de interlocução entre professores da educação básica com alunos do primeiro período do curso de licenciatura em Educação Física. $O$ espaço tem a intenção trazer provocações quanto a construção de uma identidade profissional logo no início do curso, acreditando na potência envolvida na interlocução do curso de licenciatura e os professores da educação básica, socializando as suas trajetórias e os seus saberes construídos na prática (NÓVOA, 2009).

Para, além disso, tentamos por meio do documentário compreender e valorizar os conhecimentos que esses professores convidados construíram durante a carreira docente. Deste modo, neste trabalho, pretendemos aprofundar as bases teóricas que dialogam com a ideia central do documentário e as questões que tecem o cenário docente, sendo ele composto pelas trajetórias da carreira, a identidade e a profissão docente. Em seguida, apresentaremos alguns pontos do contexto de produção, detalhando cada etapa desse processo e, por último, construiremos uma reflexão final, por meio de três notas reflexivas.

\section{REFERENCIAL TEÓRICO}

Pensando no conjunto de saberes e em tudo o que envolve a profissão docente, deparamo-nos com temáticas plausíveis de discussão na constituição do referido trabalho. Temáticas essas que traremos ao longo desta seção, buscando observar a existência de especificidades na constituição identitária e na trajetória da vida profissional do professor. Sobre a carreira docente, mobilizaremos o trabalho de Michael Huberman (1995), mais especificamente, o seu texto sobre o Ciclo de Vida Profissional dos Professores. No que se refere à discussão sobre a identidade profissional, apoiaremo-nos nos conceitos de identidade de Claude Dubar (2003), bem como no trabalho do professor português António Nóvoa (2009), que trará discussões acerca da profissão docente, trazendo um debate para a formação de professores e suas implicações na atuação profissional.

E, por último, abordaremos a temática sobre os saberes que constituem a prática profissional e, para isso, dialogaremos com os autores Tardif, Lessard e Lahaye (1991) e a ideia de que a profissão docente é construída de saberes plurais. Nesse contexto, os professores transformam suas relações de exterioridade e interioridade de sua prática por influência dos saberes e meios pedagógicos que estão inseridos ao decorrer de sua trajetória no magistério. 


\subsection{AS ETAPAS DA CARREIRA DOCENTE}

$\mathrm{Na}$ tentativa de entender a vida profissional do professor, Huberman (1995) traz uma reflexão em relação ao ciclo de vida profissional dos professores e lança seu olhar na perspectiva da "carreira". Para o autor, o conceito de carreira apresenta vantagens diversas, pois permite traçar comparações entre pessoas em seu exercício profissional e também "trata-se de estudar o percurso de uma pessoa numa organização e bem assim de compreender como as características dessas pessoas exercem influência sobre a organização e são, ao mesmo tempo, influenciadas por ela" (HUBERMAN, 1995, p. 38).

Sobre o conceito de desenvolvimento da carreira, Huberman (1995) o destaca como um processo e não uma sequência de etapas fixas, pois para alguns o processo pode ser linear ou para outros pode haver patamar. Pensando nisso, o autor categoriza a vida profissional do professor por anos na carreira e fases da carreira.

Sendo assim, primeira etapa seria o início na carreira, fase de "sobrevivência" e "descoberta". Sobrevivência no sentido de ter o primeiro confronta o "choque do real" com a profissão e a descoberta, seria o entusiasmo inicial, de estar assumindo uma turma, uma responsabilidade (HUBERMAN, 1995, p. 39). A segunda etapa, estabilização, seria a fase de segurança, entusiasmo e maturidade. Além de um sentimento de segurança pedagógica, o autor afirma que essa fase também é uma fase de

\footnotetext{
pertencimento a um corpo profissional e momento de independência. Muitos professores falam mesmo de "libertação" ou de "emancipação". Uma vez colocadas, em termos de efetivação, as pessoas afirmam-se perante os colegas com mais experiência e, sobretudo, perante suas prerrogativas, o seu modo próprio de funcionamento. (HUBERMAN, 1995, p. 40).
}

A etapa de diversificação constitui-se de uma ramificação, sendo chamada de divergência positiva, na qual o professor mostra mais empenho e entusiasmo de continuar na carreira, buscando diversificar suas aulas e materiais didáticos, e divergência negativa, no sentido de possuir medo de "cair na rotina" e para isso busca novos desafios. Na etapa de serenidade e distanciamento afetivo, o professor possui um momento de reflexão e satisfação pessoal e ao mesmo tempo em que tem um sentimento de nostalgia também se sente satisfeito, pois consegue ter serenidade em diversas situações na sala de aula ou fora dela. Por fim, a etapa de desinvestimento, neste momento o professor opta por se distanciar das reflexões escolares e se aproxima das reflexões pessoais. Segundo as análises realizadas, o autor afirma que no final da carreira profissional "a postura geral é, até certo ponto, positiva; as pessoas libertam-se, progressivamente, sem o lamentar, do investimento no trabalho, para consagrar mais tempo a 
si próprias, aos interesses exteriores à escola e a uma vida de maior reflexão, digamos mesmo de maior carga filosófica" (HUBERMAN, 1995, p. 46). Em suma, essas etapas explicitadas pelo autor não se apresentam em um modelo rígido para a carreira dos professores, ou seja, não define que todos vivenciem as mesmas etapas e na mesma ordem.

\subsection{A IDENTIDADE E A PROFISSÃO DOCENTE}

No que tange à construção de uma identidade profissional e discussões acerca da profissão docente, o curso de formação de professores no Brasil tem encontrado o desafio no sentido de aproximar o licenciando de seu espaço profissional, a escola. Tal estreitamento busca a interlocução dos conhecimentos pedagógicos, aprendidos na graduação, em diálogo com os conhecimentos na prática e com a profissão em si (NÓVOA, 2009). Deste modo, reconhecendo o distanciamento entre a formação e a profissão, o autor assinala que "a formação de professores está muito afastada da profissão docente, das suas rotinas e culturas profissionais" (NÓVOA, 2009, p. 1), tornando mais complexa a construção, por parte do licenciando, de uma identidade docente.

A construção dessa identidade docente, do ser professor, é algo que deveria ser uma busca de todo o corpo docente que constitui um curso de formação de professores, assim como deveria ser a incessante "luta" dos alunos para assumir essa identidade. Neste caminho, Nóvoa $(2009$, p. 3) tenta trazer essa articulação ao dizer que "é na escola e no diálogo com os outros professores que se aprende a profissão". O sociólogo francês, Claude Dubar (2003), também destaca que o trabalho é primordial para a construção da identidade profissional. Além disso, o autor traz uma discussão relativa às "formas identitárias", pois "o trabalho está no centro do processo de construção, destruição e reconstrução das formas identitárias” (DUBAR, 2003, p. $51)$.

Muitos licenciandos vêm passando pelo curso de formação de professores e não têm se reconhecido como tal. Talvez essa identidade só apareça na prática profissional, sendo um desafio a ser superado no processo de formação. Dubar (2003), no texto "formação, trabalho e identidade profissional", tenta detalhar as relações entre os três termos e busca traçar uma relação com o termo "mundo vivido do trabalho" e da "concepção de formação" (DUBAR, 2003, p. 45).

Desta forma, Nóvoa (2009) e Dubar (2003) alinham-se na compreensão de que a identidade profissional está diretamente associada ao trabalho. Especificamente, Nóvoa (2009) 
traz um recorte diretamente associado à construção da identidade docente dentro do processo de formação.

Compreender os sentidos da instituição escolar, integrar-se numa profissão, aprender com os colegas mais experientes. É na escola e no diálogo com os outros professores que se aprende a profissão. $\mathrm{O}$ registro das práticas, a reflexão sobre o trabalho e o exercício da avaliação são elementos centrais para o aperfeiçoamento e a inovação. São estas rotinas que fazem avançar a profissão. (NÓVOA, 2009, p. 3).

Dessa forma, refletindo sobre os desafios contemporâneos para a formação de professores, o autor defende cinco teses que passam pelo estudo de casos concretos, o trabalho em grupo, o princípio da responsabilidade social, a dimensão pessoal da profissão e a aquisição de uma cultura profissional. Estes últimos dois aspectos dialogam diretamente com o processo e construção identitária e sublinham o papel fundamental dos professores experientes na formação dos mais jovens.

Em compêndio, na aquisição de uma cultura profissional o autor faz uma comparação entre a formação de médicos e a formação de professores, destacando que, na primeira, os alunos da graduação participam do dia a dia do hospital e acompanham os profissionais nas diversas situações, entendendo a dinâmica do trabalho e analisando cada situação. Em contrapartida, na formação de professores a realidade é outra. O graduando tem, muitas vezes, uma formação com professores especialistas que nunca tiveram acesso à escola. Com isso, destaca-se a importância de a escola retomar esse papel na formação de professor, ou seja, "a contemporaneidade exige que tenhamos a capacidade de recontextualizar a escola no seu lugar próprio, valorizando aquilo que é especificamente escolar, deixando para outras instâncias actividades e responsabilidades que hoje lhe estão confiadas" (NÓVOA, 2009, p. 8).

\subsection{SABERES QUE TECEM A PROFISSÃO DOCENTE}

Para Tardif, Lessard e Lahaye (1991), a profissão docente não é caracterizada somente por saberes decorrentes de disciplinas de cursos superiores. Os saberes docentes se compõem de uma pluralidade de saberes, tais como: saberes das disciplinas, curriculares, profissionais e os saberes da experiência. Estes últimos saberes são construídos pela experiência na profissão, na sala de aula e na escola.

Todo saber implica um processo de aprendizagem e de formação; e, enquanto mais um saber é desenvolvido, formulado, sistematizado, como acontece com as ciências e os saberes contemporâneos mais se revela longo e complexo o processo de aprendizagem que exige, por sua vez, uma formalização e uma sistematização adequadas. (TARDIF; LESSARD; LAHAYE, 1991, p. 218). 
Os saberes docentes não se reduzem a uma função de transmissão de conteúdos e conhecimentos já institucionalizados e constituídos, os saberes docentes se dão em função das diferentes relações com o corpo docente, sendo então vistos e idealizados como um saber plural, em que sua construção se dá por meio de relação de trocas de saberes e experiências com a sociedade (TARDIF; LESSARD; LAHAYE, 1991). Deste modo, os saberes da formação profissional são saberes oriundos das instituições de formação dos professores, como, por exemplo, escolas e faculdades, e é nessa categoria dos saberes que os docentes criam objetos de saber para as ciências humanas e da educação, tendo em vista introduzi-las e incorporá-las em meio suas práticas docentes, constituindo então uma formação/prática cultivada e contínua. Contudo, Tardif, Lessard e Lahaye (1991, p. 219) afirmam que "a prática docente não é apenas um objeto de saber das ciências da educação" e ela tem a capacidade de construir e transcender diversos saberes pedagógicos.

\footnotetext{
Os saberes pedagógicos apresentam-se como doutrinas como concepções produzidas por reflexões sobre a prática educativa no sentido amplo do termo, reflexões racionais e normativas que conduzem a sistemas, mais ou menos coerentes, de representações e de orientações de atividade educativa. (TARDIF; LESSARD; LAHAYE, 1991, p. 219).
}

Os saberes das disciplinas, assim como os saberes pedagógicos, são construídos por matérias/disciplinas que são cursadas na universidade, que emergem da tradição cultural e dos grupos sociais produtores do saber social. Tais saberes sociais são pertinentes da formação inicial e contínua que se integram na profissão docente, ligados a diversos campos do conhecimento que dispõe a sociedade independentes das faculdades e dos programas de formação docente. Os saberes curriculares são saberes que estão presentes e em construção junto à carreira docente e são nitidamente notórios nos discursos, objetivos, conteúdos e até mesmo métodos que a instituição escolar define como saber social (TARDIF; LESSARD; LAHAYE, 1991).

Os saberes da experiência são saberes específicos em exercícios da função da prática pedagógica em relação ao cotidiano escolar, tendo incorporação e vivência de habitus e habilidades na docência, construindo assim o saber fazer e o saber ser em meio à prática docente (TARDIF; LESSARD; LAHAYE, 1991). Ou seja, o saber da experiência vai além dos saberes aprendidos nas disciplinas, o trabalho docente que é desenvolvido no cotidiano escolar é onde surgem o que os autores chamam de saberes da experiência e que muitas vezes não são valorizados nos cursos de formação de professores por não serem considerados um saber científico. 
Em suma, mesmo com o destaque aos saberes que constituem a profissão docente, ainda assim, décadas depois, a literatura vem apontando o imperativo de aproximação entre universidade/escola e, consequentemente, os saberes oriundos dos cursos de licenciatura e os saberes da experiência (ZEICHNER, 2010; NÓVOA, 2017; PEREIRA-DINIZ, 2019). Nesse sentido, esperamos que as discussões apresentadas sobre carreira, identidade e saberes docentes possam sustentar as escolhas e ações de extensão que envolvem a construção do documentário "Fio: Tecendo a profissão docente". Os trabalhos e conceitos supracitados contribuíram para a reflexão e análise dialógica com o ciclo de vida profissional docente compreendendo as etapas que compõem a carreira docente, com os saberes da experiência que foram construídos durante sua trajetória profissional, formando continuamente a identidade do professorado.

\section{Metodologia}

O referido relato de experiência está estruturado na apresentação do contexto de produção do Documentário "Fio: Tecendo a profissão docente" e a reflexão sobre as narrativas dos professores/atores do produto audiovisual. Para esta etapa, exploração do material do documentário, apresentada na seção "Notas Reflexivas", foram mobilizadas as etapas da análise de conteúdo de Laurence Bardin (2016), destacando-se a leitura flutuante e a construção de inferências. Assim, fazem parte do corpus de análise as falas dos cinco professores/atores que estrelam o documentário Fio. É importante destacar que, para as gravações, todos os professores assinaram o termo de utilização de imagem e voz.

\section{Contexto de Produção do Documentário}

O contexto de idealização, planejamento e produção do documentário foi o projeto de extensão "EEFD Baixada: Autonomia e Construção de Conhecimento". O projeto em tela divide-se em três eixos de atuação, sendo eles: o eixo de Ensino, eixo de Divulgação Científica e eixo de Formação. Sobre o objetivo do projeto:

Criar espaços de aproximação entre a escola e a universidade, valorizando o ensino da Educação Física escolar, divulgação científica, artística e esportiva junto aos alunos da Educação Básica, bem como a construção de novos ambientes de formação docente. (PIMENTEL et al., 2018, p. 198).

O eixo de ensino é voltado para a atuação nas escolas públicas (municipais e estaduais) da cidade de Duque de Caxias, no qual realizam as suas construções pedagógicas em parceria com o professor da turma. Nesse sentido, para Barbosa et al. (2018, p.155), o eixo de ensino consiste na construção de "cenários de interação entre licenciando/escola/aluno, provocando a construção de ações pedagógicas comprometidas com a tematização dos diversos componentes 
da cultura corporal". O eixo de divulgação científica tem o objetivo de socializar os saberes que são construídos dentro da universidade, ou seja, pelos próprios professores e licenciandos. Neste eixo, é realizado o caminho inverso, quando os alunos da educação básica são levados aos espaços da Escola de Educação Física e Desporto (EEFD) e lá participam de oficinas ministradas por outros licenciandos que fazem parte das disciplinas que colaboram com a realização desse evento.

Espaço de desenvolvimento do presente trabalho, o eixo de formação tem seu foco em ações que tangem à formação e à constituição de identidade docente dos alunos da EEFD. Sobre o eixo, é possível destacar que esse eixo possibilita a

promoção de uma relação mais estreita entre os docentes das redes de ensino, docentes da universidade e os alunos do curso de Licenciatura em Educação Física, de forma a dinamizar espaços de reflexão acerca da prática pedagógica, dialogando com os saberes envolvidos na formação, tanto a inicial (licenciandos) quanto a continuada (professores atuantes). (BARBOSA; CATTAN; PIMENTEL, 2018, p. 281).

Uma das ações desse eixo é o Encontro de Formação e Profissão Docente (EFPD), que tenta estreitar essa relação entre docentes das redes de ensino e licenciandos. O EFPD reúne os alunos que estão ingressando na universidade e professores da educação básica, que estão em diferentes etapas da carreira. Nesse encontro os participantes debatem sobre os desafios da carreira docente na educação física. Em suma, são narradas as trajetórias docentes e os estágios de desenvolvimento profissional. Assim, o encontro de formação busca:

\footnotetext{
promover um debate a partir dos relatos das trajetórias dos professores convidados. As questões estão muito relacionadas às escolhas, espaços de formação continuada, desenvolvimento da carreira docente, estratégias adotadas, pontos negativos e positivos na prática pedagógica, novas propostas de atuação e questionamentos sobre os modelos metodológicos conhecidos e utilizados. (BARBOSA; CATTAN; PIMENTEL, 2018, p. 283)
}

Entendendo a organização e o impacto do EFPD, após cada edição semestral do evento os professores são desafiados a apresentar a sua trajetória profissional em um vídeo de um minuto, o chamado "Profissão em um minuto". E é com base nesta ação que o documentário se modela, porém buscando aumentar o tempo de fala dos professores convidados. O objetivo é valorizar a profissão docente, sublinhando os saberes, tempo e aprendizagem construídos na carreira profissional (TARDIF; RAYMOND, 2000), tendo um olhar reflexivo em busca de entender que saberes são esses construídos na carreira docente. Em consonância com a ação do vídeo "Profissão em um minuto", o documentário tem o objetivo de contribuir para o processo de reflexão acerca da profissão dos professores em formação e contribuir também para a construção da identidade docente dos licenciandos. Sendo assim, o documentário "Fio: Tecendo 
a profissão docente" encontra-se dentro do eixo de formação do projeto, buscando dialogar com os objetivos propostos pelo conjunto de ações sobre formação docente.

Para melhor organização na produção do documentário e, sobretudo, na apresentação de seu contexto/modo de produção, descrevemos em categorias o seu processo de construção: seleção dos professores para compor o documentário, montagem do roteiro, montagem do cronograma de entrevista e edição final.

A seleção dos professores a serem entrevistados foi balizada por alguns critérios vinculados à condição central de serem professores da educação básica da rede pública. Outro critério estava vinculado à atuação do docente na defesa pela educação pública e de qualidade. Um critério importante para garantir um documento mais representativo foi a distribuição dos entrevistados nas diferentes regiões do Estado do Rio de Janeiro, buscando um universo maior de perspectivas diferentes sobre ou desafios e as trajetórias na carreira. De início, foram indicados dez professores, sendo eles das regiões: metropolitana do Rio de Janeiro, serrana e baixadas litorâneas. Porém, por algumas dificuldades de comunicação ou recusas ao convite, apenas cinco professores participaram das filmagens, sendo dois da região metropolitana, dois da região serrana e um da região dos lagos. E, por último, o critério em relação ao tempo na carreira, buscamos professores que estivessem na fase de "diversificação e continuidade na carreira" de Huberman (1995).

Sobre o roteiro, pensamos em questões que tangenciam a formação e a carreira. Questões essas divididas em ordem de categoria e pergunta. A primeira categoria conversou sobre a apresentação e formação: local e ano de formação, desafios na formação, participação de algum grupo de estudo/pesquisa ou projeto. A segunda categoria abordou a entrada na carreira: desafios encontrados dentro da profissão; preocupações atuais com a carreira. A terceira categoria tematizou as realizações na carreira e a quarta categoria destacou as pautas de luta pela valorização da profissão e carreira docente.

O cronograma foi organizado em quatro encontros para a realização das filmagens (Quadro 1). O primeiro encontro foi realizado em setembro de 2019 e contou com a participação de um docente da região metropolitana. $\mathrm{O}$ segundo encontro aconteceu com dois professores da região serrana, em outubro de 2019. No mesmo mês, o terceiro encontro aconteceu na região dos lagos, com um docente da cidade de Cabo Frio. O quarto encontro foi realizado em novembro de 2019 e contou com uma docente atuante na região metropolitana. Cabe destacar que todos os professores participantes assinaram um termo de autorização para ao uso de sua imagem e voz. 
Quadro 1:

Quadro 1 - Cronograma de entrevistas e características dos professores

\begin{tabular}{|c|c|c|c|}
\hline Professores & Regiões do Rio de Janeiro & Local de magistério & $\begin{array}{l}\text { Tempo de } \\
\text { docência }\end{array}$ \\
\hline Aristóteles Vandelli & \multirow{2}{*}{ Metropolitana } & Rio de Janeiro & 31 anos \\
\hline Ana Paula & & Duque de Caxias & 18 anos \\
\hline Bruna Lombardo & \multirow{2}{*}{ Serrana } & Cachoeira de Macacu & 14 anos \\
\hline Alexandre Calazans & & Nova Friburgo & 12 anos \\
\hline Gilmar Dias & Região dos Lagos & Cabo Frio & 13 anos \\
\hline
\end{tabular}

Fonte: Os autores.

Na etapa de edição final, foi pensada a organização da montagem do documentário, abordando questões técnicas sobre o processo de edição do vídeo, ou seja, planejar quantos minutos terá o vídeo, enredo da narrativa e sequência de cenas. Sobre o conteúdo, a análise do material filmado contribuiu para montar o desenho das cenas, buscando trazer os pontos mais relevantes para o objetivo do documentário.

Sobre a questão técnica, o vídeo tem curta duração, tendo em torno de sete minutos de duração. Inicia o curta com a frase de impacto trazida por uma professora: "existe uma confusão muito grande do professor da escola pública com o campo do amor [...] e o profissional que é a formação, a qualificação, o processo formativo. Ninguém vira pro médico e diz "ah! Ele nasceu pra isso [...] a relação que se faz é de reconhecimento profissional”, e logo após dissecar trazendo as outras categorias escolhidas. A narrativa do documentário deu ênfase à construção de identidade profissional, à valorização e desvalorização da carreira e, por fim, aos saberes da experiência que se constroem no ato do professorado. Em suma, o processo de edição final tem a importância de conseguir agrupar o objetivo do documentário e abrir caminhos reflexivos para aqueles que o assistem, fomentando novos conhecimentos sobre a profissão docente.

\section{Notas ReFLeXivas}

Nesta seção, a partir das experiências relatadas, nos depoimentos dos professores e dos referenciais mobilizados, apresentaremos três notas reflexivas sobre o processo de idealização, planejamento e produção do documentário "Fio: Tecendo a profissão docente". Essas notas reflexivas nortearão a seção com base nas categorias principais da narrativa da referida produção audiovisual: a identidade profissional; a des(valorização) da profissão; e os saberes 
da experiência. Sobre a primeira nota, relacionada à identidade profissional, entendemos que os desafios encontrados na profissão foram determinantes para a construção de uma identidade. Os professores trouxeram, em suas falas, desafios pertencentes à relação pessoal, no sentido de desconhecer/estranhar os laços de aproximação que havia na escola e entre seus atores.

A segunda nota reflete sobre a valorização da profissão e sinaliza que os professores participantes, em sua maioria, não consideram a profissão valorizada. Foi possível observar esta percepção docente em falas como "a gente está sendo cada vez mais massacrado pelo poder público", "outras ferramentas tomam conta do papel de professor, como o ensino a distância". Sobre a desvalorização salarial, um professor cita que está há sete anos sem reajuste salarial e que isso evidencia o quanto não valorizam a profissão. Outra fala reafirma o magistério como espaço desprofissionalizado, a frase "não somos reconhecidos como profissionais" faz comparação com a valorização do médico a sua consolidada profissionalidade. Em contrapartida, a relação que se faz com o professor é de vocação, o professor tem que ser resiliente, secundarizando o papel pedagógico formativo do professor e da escola. Nesse sentido, notamos que as falas mostraram um pouco da indignação pela falta de valorização da profissão e uma busca pelo reconhecimento. Na disciplina Educação Física, uma fala evidencia outro desafio ao dizer que o professor, especificamente, tem que estar a todo momento reafirmando seu lugar na escola, enquanto as outras disciplinas por si só conseguem esse mérito.

A última nota reflete sobre os saberes construídos e desenvolvidos na profissão docente. Identificamos nas entrevistas com os professores que esses saberes foram disseminados por meio de propostas pedagógicas e suas produções enquanto professores da rede básica de ensino. Alguns professores mencionaram que em sua formação inicial foi necessário introduzir-se em grupos de estudos, projetos de extensão e pesquisa, pois a formação ficou limitada às aulas com os licenciandos da turma, visto que a escola e o contato com alunos só era mencionada e pensada a partir do $7^{\circ}$ período. Nesse sentido, os docentes destacam esta questão como uma das maiores fragilidades na formação inicial.

\section{CONSIDERAÇões FinAIS}

Diante do exposto ao longo do referido relato, no contexto de produção do documentário, em diálogo com as discussões teóricas sobre os saberes, a identidade e a carreira docente e, sobretudo, na reflexão sobre as falas dos professores/atores, foi possível socializar a tessitura desenvolvida entre os temas identidade, profissão e saberes docentes. O processo de construção do documentário abordou estas temáticas logo em seu momento de elaboração e, 
em seguida, na gravação. Deste modo, esperamos que a difusão deste produto audiovisual possa colocar em pauta a profissão docente em outros espaços e arenas.

\section{REFERÊNCIAS}

BARDIN, Laurence. Análise do conteúdo. Edição revista e ampliada. São Paulo: Edições 70, 2016. 279p.

COSTA, Cássia Barbosa da; LÔBO, Natália Soares Rangel; CEZARIO, Daiana da Silva et al. EEFD Baixada: cultural corporal e produção discente. In: CONGRESSO DE EDUCAÇÃO FÍSICA ESCOLAR NA PERSPECTIVA INCLUSIVA, 1, 2018, Rio de Janeiro. Anais... Rio de Janeiro: UFRJ, 2018. p. 155-159. Disponível em:

https://drive.google.com/open?id=12WzKR2ZVu8MsrP8ETM2eNbqIVXM861ti. Acesso em: 12 jun. 2020.

COSTA, Cássia Barbosa da; CATTAN, Caroline; PIMENTEL, Danielle. EEFD Baixada: identidade e profissão docente. In: CONGRESSO DE EDUCAÇÃO FÍSICA ESCOLAR NA PERSPECTIVA INCLUSIVA, 1, 2018, Rio de Janeiro. Anais... Rio de Janeiro: UFRJ, 2018. p. 280-284. Disponível em:

https://drive.google.com/open?id=12WzKR2ZVu8MsrP8ETM2eNbqIVXM861ti. Acesso em: 12 jun. 2020.

DUBAR, Claude. Formação, trabalho e identidades profissionais. In CANÁRIO, Rui (Org.). Formação e situações de trabalho. Porto: Porto Editora, 2003. p. 43-52.

GATTI, Bernadete Angelina. A formação de professores no Brasil: características e problemas. Educação \& Sociedade, Campinas, v. 31, n. 113, p. 1355-1379. 2010. Disponível em: https://www.scielo.br/pdf/es/v31n113/16.pdf. Acesso em: 12 jun. 2020.

HUBERMAN, Michael. O ciclo de vida profissional dos professores. In: NÓVOA, Antônio. Vida de professores. Porto: Porto Editora, 1995. p. 37-46.

NÓVOA, Antônio. Para uma formação de professores construída dentro da profissão. Lisboa: Educa, 2009. p. 2-9. Disponível em:

http://www.revistaeducacion.educacion.es/re350/re350_09por.pdf . Acesso em: 12 jun. 2020.

PIMENTEL, Danielle; VASCONCELLOS, Danielle Machado; CARNEIRO, Gabriel de Sousa Vandelli. O Encontro De Lá pra Cá como espaço de aproximação entre a universidade e a escola. In: CONGRESSO DE EDUCAÇÃO FÍSICA ESCOLAR NA PERSPECTIVA INCLUSIVA, 1, 2018, Rio de Janeiro. Anais... Rio de Janeiro: UFRJ, 2018. p. 280-284. Disponível em:

https://drive.google.com/open?id=12WzKR2ZVu8MsrP8ETM2eNbqIVXM861ti. Acesso em: 12 jun. 2020.

TARDIF, Maurice; LESSARD, Claude; LAHAYE, Lousie. Os professores face ao saber: esboço de uma problemática do saber docente. Teoria e Educação, Porto Alegre, n 4, p. 215233, 1991. 
TARDIF, Maurice; RAYMOND, Danielle. Saberes, tempo e aprendizagem do trabalho no magistério. Educação \& Sociedade, Campinas, n. 73, p. 209-244, 2000. Disponível em: https://www.scielo.br/pdf/es/v21n73/4214.pdf. Acesso em: 12 jun. 2020.

ZEICHNER, K. Repensando as conexões entre a formação na universidade e as experiências de campo na formação de professores em faculdades e universidade. Educação, v. 35, n. 3, p. 479-504, maio/ago 2010. Disponível em:

https://periodicos.ufsm.br/reveducacao/article/view/2357/1424. Acesso em: 7 jul. 2020.

Recebido em: 20 de junho de 2020.

Aprovado em: 24 de agosto de 2020. 